\title{
The Role of Substitute Industries for Revitalizing Shrinking Cities
}

\author{
Jakob Schackmar $(\mathbb{D}$, René Fleschurz $\mathbb{1}$ and Karina Pallagst * * \\ Department International Planning Systems, Technische Universität Kaiserslautern, Pfaffenbergstr. 95, \\ 67663 Kaiserslautern, Germany; jakob.schackmar@ru.uni-kl.de (J.S.); rene.fleschurz@ru.uni-kl.de (R.F.) \\ * Correspondence: karina.pallagst@ru.uni-kl.de
}

\begin{abstract}
In past decades, many cities and regions have underwent structural transformations-e.g., in old industrialized "rust belts" or in peripheral rural areas. Many of these shrinking cities have to face the challenges of long-term demographic and economic changes. While shrinkage is often related to post-industrial transformations in the USA, in other countries, such as Germany, for example, the causes are related to changing demographics with declining birth rates and the effects of the German reunification. Many cities have tried to combat shrinkage and have thus developed a variety of policies and strategies such as the establishing of substitute industries. To assess the sustainability of this approach, this paper investigates the cities of Cleveland, USA and Bochum, Germany in a comparative analysis following the most similar/most different research design. The paper shows that substitute industries might lead to new development paths for shrinking cities; however, whether these paths stimulate sustainable development is dependent on those who are benefiting from these developments and to what extent.
\end{abstract}

Keywords: substitute industries; shrinking cities; urban development; sustainable development

check for

updates

Citation: Schackmar, J.; Fleschurz, R.; Pallagst, K. The Role of Substitute Industries for Revitalizing Shrinking Cities. Sustainability 2021, 13, 9250. https://doi.org/10.3390/su13169250

Academic Editor: Luigi Dell'Olio

Received: 7 May 2021

Accepted: 11 August 2021

Published: 18 August 2021

Publisher's Note: MDPI stays neutral with regard to jurisdictional claims in published maps and institutional affiliations.

Copyright: (c) 2021 by the authors. Licensee MDPI, Basel, Switzerland. This article is an open access article distributed under the terms and conditions of the Creative Commons Attribution (CC BY) license (https:// creativecommons.org/licenses/by/ $4.0 /)$.

\section{Introduction}

In many countries all over the world, cities and regions have underwent structural transformations-e.g., in old industrialized "rust belts" or in peripheral rural areas [1-9]. Many of these shrinking cities have to face the challenges of long-term demographic and economic changes $[10,11]$. In Germany, for example, changing demographics with declining birth rates and the effects of the German reunification were triggers for shrinkage. In the USA, shrinkage has been largely caused by post-industrial transformations $[8,10]$ (pp. 6-16).

Many cities have gone through stages of downsizing and, in this respect, they have experienced a phenomenon wherein the type of industry which promoted growth in the past (e.g., mining, manufacturing, steel industries) was dismantled in the wake of globalization and post-industrial transformations [12-14]. For this reason, shrinking cities often seek different (economic) paths, providing more innovative job opportunities [15]; yet, substitute industries are widely varied [16]. The question is: Is always the most sustainable path that is chosen for a future-oriented revitalization? A large number of cities have applied comparable strategies: In many cases, branches such as tourism, logistics, culture, education, and medical facilities, high-tech clusters, and green infrastructures have been created [10].

This article investigates substitute industries as a revitalization tool for shrinking cities, putting into question whether the chosen paths offer sustainable approaches for shrinking cities. The underlying hypothesis is that, in light of global initiatives such as sustainable development goals (SDGs) designed to steer global (urban) development in a more focused way towards more inclusive, healthier, and environmentally friendly cities [17], shrinking cities are in need of (urban) redevelopment and revitalization, and therefore have the potential to implement these goals. After explaining the causes and consequences of shrinkage and the routes leading to new economic opportunities, the 
paper presents substitute industries as part of a (sustainable) redevelopment strategy and general plan for shrinkage in a sustainable way. This is followed by a section introducing the materials and methods of the research. Then, in order to offer insights into the general paths of shrinkage, and to reflect upon the proposed strategies, cases of shrinking cities attempting to generate substitute industries are presented in the examples of Bochum, Germany, and Cleveland, USA. Finally, we draw conclusions, highlighting the role of substitute industries for reviving shrinking cities and the need to further investigate the many paths of revitalization shrinking cities are undertaking.

\section{Causes and Consequences of Shrinkage and the Quest for New Economic Opportunities}

Since the turn of the century, shrinking cities have emerged as a field of interest for scientific research. For 20 years now, urban planners have tried to tackle the issue of urban shrinkage, both in theoretical approaches as well as in specific urban development strategies, to counteract the effects caused by shrinkage [18].

The Shrinking Cities International Research Network (SCiRN) defined a shrinking city as an urban area with a population of at least 10,000 inhabitants that has been or is currently facing large population losses for a period of at least two years. Adding to that, the city is facing structural economic transformations and its associated consequences [5].

Yet, the issue of shrinking cities and its causes and effects, and the related policies designed to deal with shrinkage, has not fully been explored. What characterizes shrinkage as a multidimensional process is, first of all, the specific situation each shrinking city is embedded in (national as well as regional and local). Moreover, there are many different actors involved in the revitalizing of shrinking cities, and over the years various approaches for addressing general shrinkage, particularly in urban planning, have been brought forward [19].

Based on the discussion of the SCiRN network, which describes shrinkage as a factor of economic transformations, the following paragraphs portray the causes and consequences of shrinkage, which are in many aspects related to declining economies.

When the discourse on shrinkage started out at the beginning of the 2000s, scholars were engaged in analysing the different conditions which might lead to the shrinkage of an urban entity. The following six indicators were identified as potential causes of urban shrinkage as a particular concern in monostructured regions:

- Outmigration of population (short distance suburbanization and long-distance migration);

- number of jobs;

- lack of a skilled workforce;

- deindustrialization (in general) of relevant economies;

- $\quad$ political decisions on all layers of government;

- real estate marked/state of building stock [20,21].

These developments can occur simultaneously or in parallel and they depend on various aspects such as locational factors or individual circumstances. Moreover, the aforementioned causes relate to shrinking phenomena in economic terms, sometimes also the collapse of entire industrial branches. Job losses count as an accompanying and intensifying effect.

In addition to a general increase in life expectancy and therefore an aging population, there is also an outmigration of mostly young and very qualified citizens moving towards city (centres) in general [22].

A weakened industrial sector in mining or manufacturing is a direct cause of the decline of the economic basis of the city or region. Consequently, a lower number of jobs and related job training possibilities are available, leading to a labour shortage in the end through the increased outmigration of young and well-educated people [22,23] (p. A4). It can therefore be stated that the population is out-migrating if there is no prospect for a job and there is a lack of opportunities for training or higher education [24] (p. 7f). 
With the economy in decline, a downward spiral is set in motion, which is influences other branches of the economy, resulting in a lower competitiveness in terms of attracting businesses, investments, and a qualified workforce [25] (pp. 94-95). Here, for example, a less competitive workforce, lower investments from outside the city, and a declining purchasing power within the city (due to higher unemployment and outmigration) have to be mentioned [26,27] (p. 99f).

The problems of high unemployment rates and an out-migration of the younger population on the one hand, and the general income and expenditure policies of the municipal budgets on the other hand, results in a structural loss of tax income for the respective city. In addition, the decline of large companies in an area which is monostructured in economic terms can quickly lead to precarious financial conditions [23,26,28] (pp. A7-A8).

The consequences of this downwards spiral can be summarized as having a population decline, high unemployment rates, a loss of purchasing power and property tax, the declining financial strength of private and public budgets, declining investments by private and public households, and a loss of image for the entire city. These factors often characterize the process of urban shrinkage [29] (p. 12), and they also demonstrate the complexity of the phenomenon.

Thus, urban shrinkage is a multidimensional process. The consequences and effects of shrinkage illustrate the broad spectrum of challenges municipalities affected by shrinkage have to deal with. Economic transitions initiate a spiral of self-accelerating decline, resulting in sometimes existential consequences for the municipalities. The question which is often posed in this respect, is: If and how can urban shrinkage be stopped, mitigated, or prevented, and how do measures of revitalization come into play in regards to urban planning strategies and/or economic countermeasures?

The old industrial and post-industrial regions of the mining and steel industries in western Germany, in particular in the former monostructured Ruhr area, serve as a characteristic model of shrinkage, its causes and consequences, and also for the measures with which to deal with shrinkage $[30,31]$ (p. 1). However, this is not a phenomenon seen only in Germany. As this development is happening around the globe in old industrial cities or regions, and also in the north-eastern part of the US, the so-called rust belt, can be seen as a prominent example. Many cities located in this region have had, and continue to, face a decline in both the population and the economy in the last decades of the 20th century. Long enduring post-industrial transformations have changed the old industrial region, which is today a laboratory for new approaches and instruments trying to tackle shrinkage [19,32]. The two case study cities presented in this paper, Bochum in Germany, and Cleveland in the USA, are both located in these areas of shrinkage and decline, the former in the Ruhr area, the latter in the rust belt.

As shrinking cities move through phases of downsizing, it is not always an easy process to discover the economies which provided growth in former times, such as mining, manufacturing, and steel industries, which do not fit into an era characterized by globalization, transformations, and global crises. Moreover, it turns out that creating or attracting new and alternative economies for workers who have lost their jobs due to structural change is a lengthy and complex task [33]. One path to decelerate the downwards spiral seems to be generating so-called substitute industries [16], yet the question remains if and how these strategies play a role in a more sustainable and liveable future for shrinking cities.

\section{Utilizing Substitute Industries as Part of a (Sustainable) Redevelopment Strategy}

Despite the fact that problems and transitions are manifold in shrinking cities, as we learned in Section 2 of this article, it is not always easy for cities, in particular their political leaders, to accept that there is an ongoing decline, and to start thinking about countermeasures. In this respect, many cities have developed policies and strategies to deal with both shrinkage and economic decline in general. Meanwhile, scholars shrinking cities have also brought forward typologies of strategies which are applied in shrinking cities. 
What is more, the application of specific strategies is influenced by the level of acceptance of shrinkage in the respective city [34].

When it comes to choosing these strategies, in order to revitalize the economic basis, many cities consider more innovative or at least alternative branches such as tourism, logistics, culture, education, and medical facilities, as well as high-tech clusters or green economies.

In the following sections, substitute industries are examined in more detail as a potential concept for revitalization. This includes a definition of the concept, an introduction to the different types and their respective tasks in relation to the urban economy, and an outline of the potential limitations the concepts might encounter.

In order to understand substitute industries in the context of this article, an explanation and classification of this concept is required. Many cities affected by shrinkage have lost a major company or even an entire economic branch, and, as we learned in Section 2 of this paper, are caught in the problems of a declining downward spiral. Substituting the "old" economy with a new one is considered an important factor for a future-oriented development, as these new economies might provide new opportunities for work, jobs, and, in general, new impulses of development [34,35] (pp. 23-25). Thus, they offer paths for the city and its inhabitants to regain stability and prevent further shrinkage [33].

In general, international literature has defined substitute industries in a socio-economic perspective, by means of which a city can stabilize itself economically, financially, and socially in the shrinking process, and where growth accents can be set [36,37].

Investigating the term "substitute industries" reveals that it is used in the English language to describe the primary replacement of jobs as well as the strategies for the general revitalization of the local economy. The expression "substitute industries" does not provide any specific information about a certain economic branch or sector. It is not surprising that substitute industries have been discussed, especially in the US. Since manufacturing and mining companies have migrated or gone bankrupt, there has not been a shrinking city in the US rust belt that has not tried to attract substitute industries or initiated a different approach to economic stimulation [34,38] (pp. 83-85). This has ranged from new urban regeneration strategies in terms of infrastructure-based economic development such as "airport cities" to economic approaches such as the promotion of "creative class" developments [39].

What adds to this is a diversified economic portfolio: in trying to attract new businesses from a variety of industries, cities get the chance to (re)create jobs in various economic branches. This, in turn, would lower the dependency on a monostructured economy. In this case, the correct label would be "establishing alternative industries" [32,37]. But urban settings are highly complex. Therefore, not every city has the potential to jumpstart each type of substitute industry. This is influenced by location, actors (citizens, political leaders, planners), governance modes, and many other aspects. Moreover, a certain push, or what Sorensen has called "critical juncture", might be required to activate a specific approach [40] (p. 25f).

One could ask at this point, whether the promoting of substitute industries in dealing with shrinking cities may already offer more sustainable development paths for these cities; hence, not trying to "fix" what has been lost during the last decades but dealing with the potentials that are offered today in order to bring the downward spiral to a stop. A sustainable (re)development of shrinking cities could offer new perspectives on the efforts made to deal with shrinking cities, yet more case study-based research might be needed in this respect.

The next Section investigates how sustainability and planning for shrinkage might work together.

\section{Sustainability and Planning for Shrinkage}

The current understanding of sustainability has emerged during the course of the past 30 years. It was shaped by the world commission for environment and development 
and aimed at balancing today's resource consumption without being at the expense of future generations [41] (p. 41). This resulted in the Agenda 21, in which the members of the United Nations committed themselves to sustainable development. This included the improving of the quality of housing and settlement in ecological, economic and, social terms. Here, the aim was to measure the space required for the development of settlements through environmentally friendly spatial planning and land use.

Cities are seen as key actors for greater sustainability in general and have become more of a focus point in discussions around the issue, as more people are moving towards urban centres. Studies have shown that, no matter how different in population size, economic status, or administrative set up, they nevertheless face similar or the same conflicts with sustainability strategies and plans, namely insufficient participation or ambitiousness and, at some points, overlapping municipal strategies, as well as a lack of long-term commitments. A need for more individual setups and interpretations has been attested for [42]. However, the global attention to cities has often focused on the development of new constructions and an expansion of land use [43] (p. 47), yet what does sustainability mean for shrinking cities? In an area such as shrinking cities, with limited resources, these resources must be handled with even greater care than in growing cities. Combing existing initiatives and saving resources through this lens could already be a sustainable approach.

As described earlier in this paper, it is becoming apparent that Germany as well as the US are not only dealing with growth issues but also the task of accommodating and dealing with shrinkage [44] (p. 276), resulting in both the consumption of land as well as the land that is falling out of use. The latter is an especially apparent issue in shrinking cities, as with population decline and a rise in economic brownfield sites, land becomes vacant. A sustainable way to deal with land use in this matter would, in general, be to balance land markets. However, shrinking and growing cities are usually not neighbouring cities and, since land use cannot be addressed as it could be with other goods or resources, new ways towards sustainable development need to be found [45].

Another concern is that shrinkage occurs especially in (economically) monostructured cities. A sustainable change in land use therefore requires not only the development of unused land but also a diversified mix of uses, not only in economic terms but also in regards to residential, office, retail, leisure, public (green) space, accommodation, and other types of uses [11]. This should, in turn, contribute to the creating of vibrant and liveable urban settings.

Combining strategies of sustainable economic and urban development in shrinking cities offers additional potential to turn formerly brownfield spaces and vacancies into "green" developments, such as spaces for rain/storm water management, that may enhance urban climate adaptability or generally contribute to healthier urban environments. Nevertheless, it must be stated that these types of developments do not create direct economic benefits that would keep the city from shrinking any further.

After presenting the materials and methods used for this research, the article investigates the cases of Cleveland and Bochum. Looking at these cases demonstrates that the development of substitute industries in shrinking cities can implement economic revitalization and, at the same time, enhance sustainability along the lines mentioned above.

\section{Materials and Methods}

The objective of the research was a comparative investigation of changes in planning systems and planning cultures in view of shrinking cities in Germany and the USA, in particular, to analyse planning strategies and instruments connected with urban shrinkage and its causes in a comparative mode.

The methodological approach was based on carrying out and analysing case studies. This involved a combination of desk research, qualitative semi-structured interviews with stakeholders, site visits, and a workshop with stakeholders to verify the results.

- Regarding the planning cultural context, the selection of the two countries Germany and the USA followed the most different systems approach, based on comparative 
studies in political science (according to Otner [46]). Yet, the selection of Bochum and Cleveland followed the most similar systems approach (according to Pierre [47]). Both cities displayed similar paths of shrinkage, comparable numbers of population, and related branches of industry and economy. The approach for this comparative analysis was based on the search for common features and differences (variation finding) [48]. Furthermore, the selection of case study cities was based on the following hypothesis: Severe problems regarding shrinkage are present in both cities and lead to a change in traditional planning strategies and the use of established instruments.

- Planning strategies are embedded in the local planning cultural context and cannot or hardly be transferred to other cities despite similar conditions.

- Despite the limited transferability, there are signs of convergence in the development of planning cultures caused by shrinkage.

Additionally, the results of the EU COST Action Cities Regrowing Smaller (CIRES) showed that, of all European cities with more than 10,000 inhabitants, those with a population between 300,000 and 500,000 were most often affected by shrinkage [11]. Moreover, in both of the two cities, major strategies for innovative solutions regarding shrinkage-related problems have been applied.

To identify examples of the best or worst practices, as well as the advantages and disadvantages of used strategies and measures for shrinking cities, the method of embedded case study research was applied. With this approach, an in-depth analysis of actors, their motivations, actions, opportunities, and limits, could be assessed. According to Yin [49], case study research is based on six sources of information: documentation, archive material, interviews, direct observation, passive observation, and physical/cultural artefacts.

As a starting point, the current state-of-the-art research was analysed by studying academic literature related to shrinking cities, sustainable urban development, and the revitalization of cities in Germany and the USA. Moreover, a collection of statistical data was carried out in order to analyse the case study cities' paths of decline. The core of the work was carrying out 40 semi-structured interviews in the years 2017 and 2018 in the cities of Cleveland and Bochum with actors in government (city planning departments, regional entities, ministries), political decisionmakers, NGOs, developers, and academics.

Interview questions regarding both cities focused, among others, on the current situation regarding population development and housing, possible critical points in the history of urban development (e.g., major shutdowns, outmigration, etc.), the perception of the problem of population loss both by city officials and the public, and the specific policies in use in neighbourhoods with high vacancy rates to stabilize prices and improve the quality of life. In addition, specific aspects regarding the cities were considered, such as suburban development in Cleveland and the metropolitan/regional setting of Bochum. Two site visits were carried out, during which the situations in the inner cities as well as a range of neighbourhoods of Cleveland and Bochum were photographed and documented.

To be able to generalize the findings, the results were verified in a workshop (2018 at Kaiserslautern) engaging a select number of stakeholders of the case study cities.

\section{Cases of Shrinking Cities Attempting to Generate Substitute Industries}

In recent years, the authors investigated several cases of shrinking cities, for the most part in Germany and the USA. The following paragraphs highlight two cases of shrinking cities as examples of leveraging substitute industries: Cleveland, USA, and Bochum, Germany. These cities were selected based on their paths of economic transitions-from manufacturing to other, somewhat more innovative, economic branches. The research presented here is based on the research project PlanShrinking ${ }^{2}$, funded by the German Research Association (DFG). The project applied case studies as a methodological approach, involving literature analysis, data analysis, and semi-structured interviews with stakeholders from the case study cities. Preliminary research results were then validated in the form of a workshop at Kaiserslautern in the year 2018 with experts from the respective cities. 
Shrinking cities were chosen as the main focus for this research. The social, economic, and spatial transformations triggered by shrinking processes present a specific challenge for urban development and spatial sciences [4,6,50-52]. In particular, planning processes and planning cultures are expected to change when dealing with shrinkage [53] as the causes and effects of shrinkage are similar in different countries [38,52], but national discourses and suggested solutions will most likely differ, therefore international comparative research is needed.

In addition, it has to be considered that planning realms in the USA and in Germany offer very specific yet different planning cultural settings. While the US planning culture has been labelled "market oriented" [54], the German one offers a more elaborate multilevel planning system, often criticized as being inflexible [55].

The comparative method considered cultural, social, economic, and ecological aspects, as well as issues of land use. Germany, as well as the US, have implemented planning strategies in order to actively deal with shrinkage [9]. The diverse range of strategies has included substitute industries such as tourism, demolitions (right-sizing), and green infrastructure [9]. The smart implementation of the "right" strategies to restructure a shrinking city is crucial for a development that takes the conditions of shrinking into account. Hollander et al. aptly enquired: "What are the viable options for a shrinking city-redevelopment, landscape beautification, historic preservation, ecological restoration, temporary uses, demolition of neighbourhoods, benign neglect, or perhaps something else? How can a shrinking city evaluate what works and what doesn't? How does it balance short-term considerations against long-term ones? Economic against environmental ones?" [6] (p. 232). The same authors concluded that "shaving the edges off Youngstown, or Detroit or Dresden, will no longer suffice" [6] (p. 232), particularly when dealing with such a complex topic as shrinking cities.

\subsection{Cleveland: Focused Growth \\ 6.1.1. General Approach in Terms of Substitute Industries}

The US city of Cleveland, located in the state of Ohio in the so-called US rust belt, is a former centre of manufacturing and steel production which has experienced economic transformations, shrinkage, and nearly a 50\% loss of inhabitants since the 1960s [56]. In order to jumpstart substitute industries to compensate for the losses the city had to face (in jobs, people, and image), Cleveland has in recent years adopted a development strategy based on an attempt to establish itself as a centre for biotechnology, medical research, and medical care. In doing so, the city's approach is much in line with other rust belt cities in the Great Lakes region, also trying to innovate their economies by building on their institutions of higher education and research [57].

Apparently, this strategy has been successful, since the research and learning institutions have been major contributors to the economic transition and revival of many of the region's major metro areas, among them the city of Cleveland [57].

This approach to urban and regional development has certain advantages. Being located in an area outside the city center, a development corridor is connecting the downtown area and the University Circle neighborhood, aiming at spreading development across town. Another advantage to combined projects following the lead of the University Circle is that jobs which are created in the knowledge sector are unlikely to be shifted abroad, and offer high-skill work and high wages. Consequently, Cleveland has attempted to transform itself into a centre for innovation, thus trying to shed its rust belt image, often based on initiatives by the private sector. One of them is the Greater University Circle Initiative (GUCI), see Figures 1 and 2. The development of GUCI started as early as the 19th century when Western Reserve University and Case Institute of Technology decided to find a new location for their expansion [58]. Figures 1 and 2 show the development path in the urban fabric from historical buildings (Figure 1) up to the latest extensions with flagship architecture (Figure 2). 


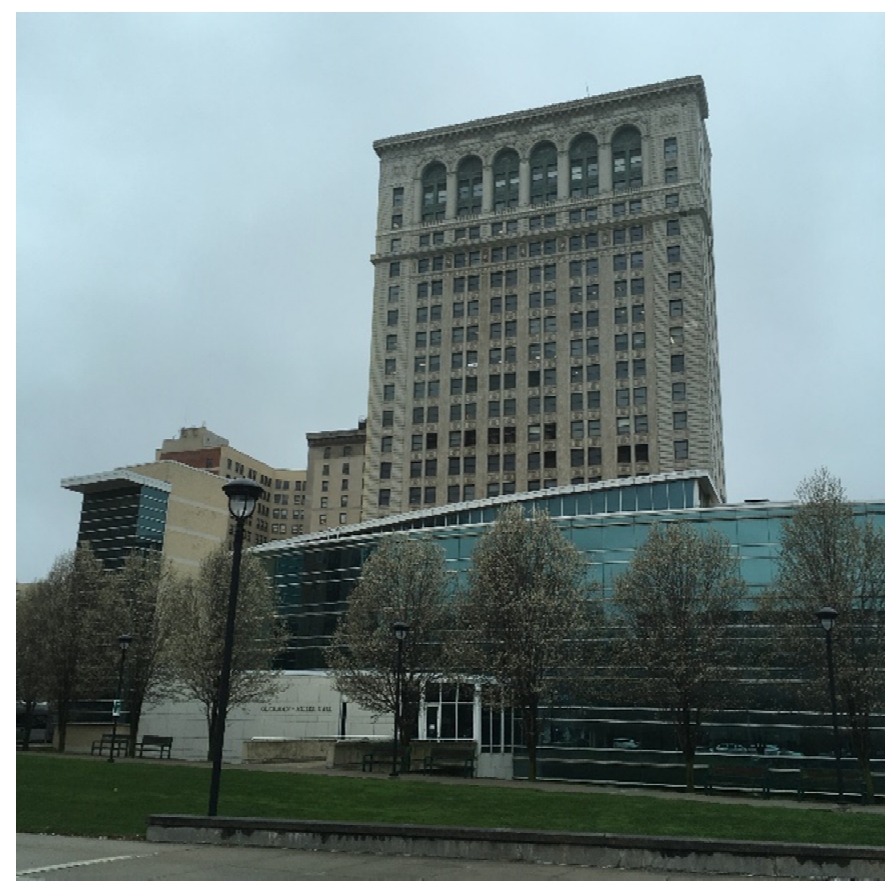

Figure 1. University Circle—old and new developments. Source: Karina Pallagst.

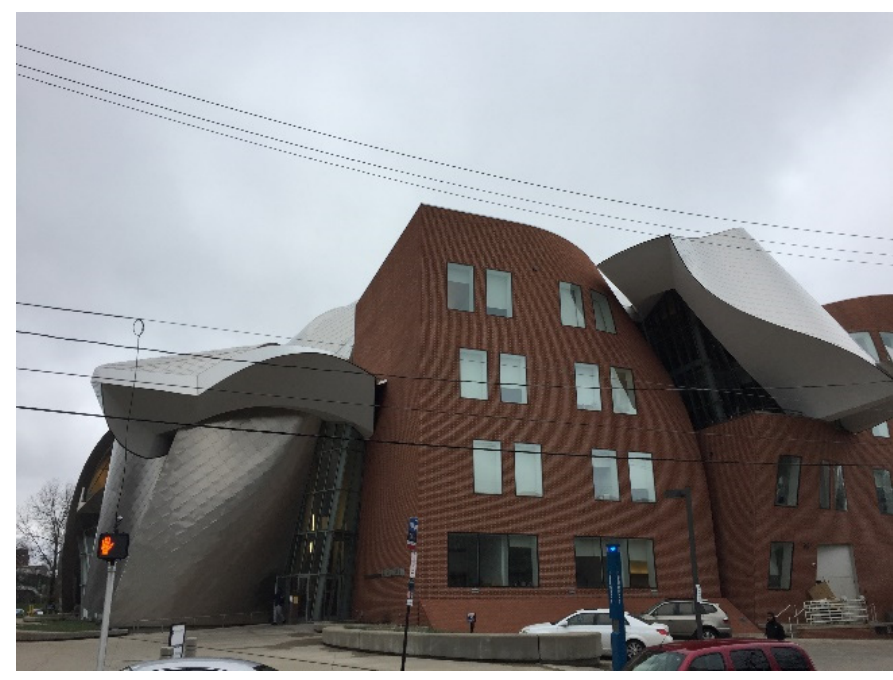

Figure 2. University Circle—flagship buildings. Source: Karina Pallagst.

Over the years many more institutions have decided to relocate to the University Circle, and the area has become a world-class centre of innovation [58]. GUCI was officially founded in 2005, supported by the Cleveland Foundation. Under the roof of GUCI, the Cleveland Foundation, the institutions of the University Circle, such as Case Western Reserve University, Cleveland Clinic, University Hospitals, the City of Cleveland, and many more, work together [58] (p. 24). The aim of the initiative is to "promote dialogue about the future of surrounding neighbourhoods catalyse and help fund projects to transform both the built environment and the lives of residents." [58] (p. 24) and therefore connect the inner city to the new development cluster for a broader and more sustainable approach throughout the city.

The collaboration provides many advantages such as a platform of discussion, transparency, a new way of working together, accountability, neutrality, continuity and the "capacity for catalytic project conception and fundraising" [58] (p. 25). In doing so, more coordination and efficiency has been achieved, resulting in a more sustainable approach for the developing of this diverse urban setting. 
GUCI have developed four areas to focus on [58] (pp. 32-33):

1. Institutional partnership and basic elements of the initiative which enable the Greater University Circle Initiative to survey growth.

2. Physical development, focusing on housing and retail projects and investments in transportation.

3. Economic inclusion such as, on the one hand, motivating employees to live and consume in the neighbourhoods and, on the other hand, persuading companies and institutions to hire people who live in the neighbourhoods.

4. Community engagement by establishing new networks of neighbours.

Meanwhile, GUCI established a wide range of projects to connect institutions with surrounding neighbourhoods. Overall, private actors, together with city officials, have adopted a clear strategy to turn Cleveland into a hub for the knowledge economy. Investment is flowing into the city, programs ensure that existing communities are integrated in this transformation, and areas such as the University Circle has seen urban redevelopment. Some of these projects include the development of the so-called "Forgotten Triangle" by connecting the University Circle district with two interstate highways, creating the "Opportunity Corridor". This new boulevard is supposed to increase investment opportunities along its path but has also been criticized for favouring suburban commuters and external investors over the local neighbourhood, similar to the already existing Health Tech Corridor, connecting University Circle and Downtown Cleveland, of which the opportunities for local (neighbourhood scaled) businesses seem limited. Meanwhile, the redevelopment of the downtown area as a residential district is moving on, but again, this development does not focus on those Clevelanders who have suffered most from the city's economic downturn.

\subsubsection{Reflection on the Case}

The City of Cleveland is an exemplary case of a city once dominated by a single economic branch that has experienced significant shrinkage over the last decades. Having learned from the past, it seems, the city's government initiated a diversification strategy of the urban economy to be more resilient and sustainable in general. Following the direction of the tertiarization, Cleveland is now home to companies of various branches connected with institutions of higher education and research. The strategy of the knowledge economy is primarily lead by the GUCI, a cooperation and partnership of private and public actors working in a multi-anchor strategy.

In the light of sustainability, this can be seen as the right direction for the city, as multiple branches make the city's economy more resilient to crises, and less dependent on globalisation. The jobs created in knowledge economy-based companies are more likely to stay and not be shipped overseas, and with the physical revitalisation of the University Circle area, the quality of life and health of the city's citizens has improved. However, despite the fact that a connection to the downtown area was created by means of a development corridor, this has not yet shown the intended results, namely to spread the positive development effects of the University circle area across town.

However, it is not clear if the projects that are focusing on a small part of the city have an impact on the city as a whole. Moreover, it cannot be determined from the research whether the city administration had intentionally initiated a "sustainability strategy" with these goals in mind, or if the effects of the initiatives were set on the agenda by the GUCI. In the authors' opinion, a step towards more sustainability was successful, as the University Circle area was physically redeveloped and the attraction of new jobs has created economic recovery, especially by linking the area to the rest of the city via the development corridor and by creating links between existing projects. Moreover, it has enhanced the redevelopment of the urban surroundings, and created a higher quality of life with walkability, public (green) spaces, and local retail facilities. In general, the development has also resulted in a rise of occupancy of buildings and a rise of inhabitants in the area. 
Nevertheless, it can be observed that with such high demand for change and improvement as in Cleveland, the city does not seem to have many options than to aim for a more sustainable development with both the present and future generations in mind.

\subsection{Bochum: Eds and Meds}

\subsubsection{General Approach in Terms of Substitute Industries}

The City of Bochum is located in the German state of North Rhine-Westphalia, specifically in the Ruhr area. Much like the entire region, the city was subject to early economic decline in mining, steel production, and the manufacturing sector. Therefore, many cities of the densely-populated region have actively been trying to bring about change [33].

The city of Bochum has identified educational and medical facilities, or "eds and meds", as the route forward. Interestingly, this turns out to be a different approach compared to most of the other cities in the Ruhr area, which are all somewhat competing against each other. Moreover, eds and meds have always been important aspects for citizens. In the future, with increasing global competition for education and research resources, with the ongoing demographic change and an aging society, and with medical advances, this role will increase even further. Furthermore, the city is already home to several eds and meds activities. Bochum has acknowledged these demands and is promoting the project "health campus" as an innovative approach to boost the city's economy, which is a path building on the city's existing strengths (see Figures 3 and 4) [33,59] (p. 9).

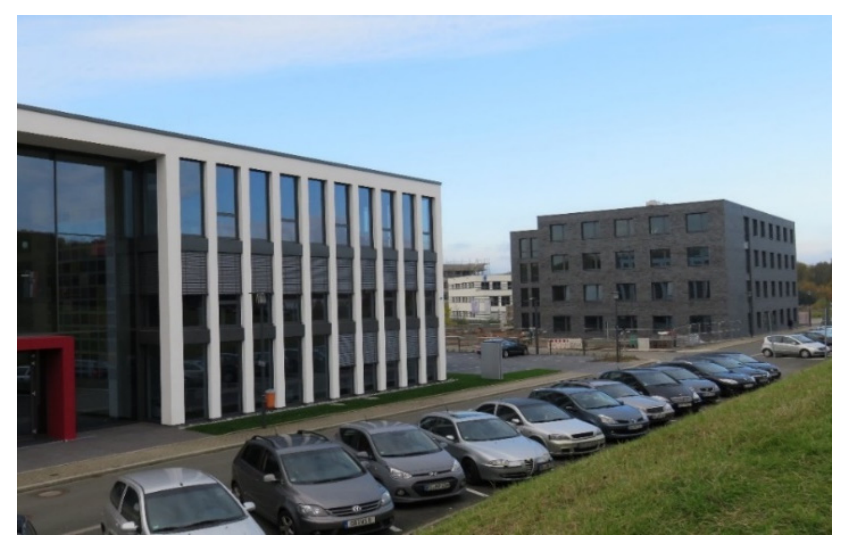

Figure 3. Health campus—new buildings. Source: Jakob Schackmar.

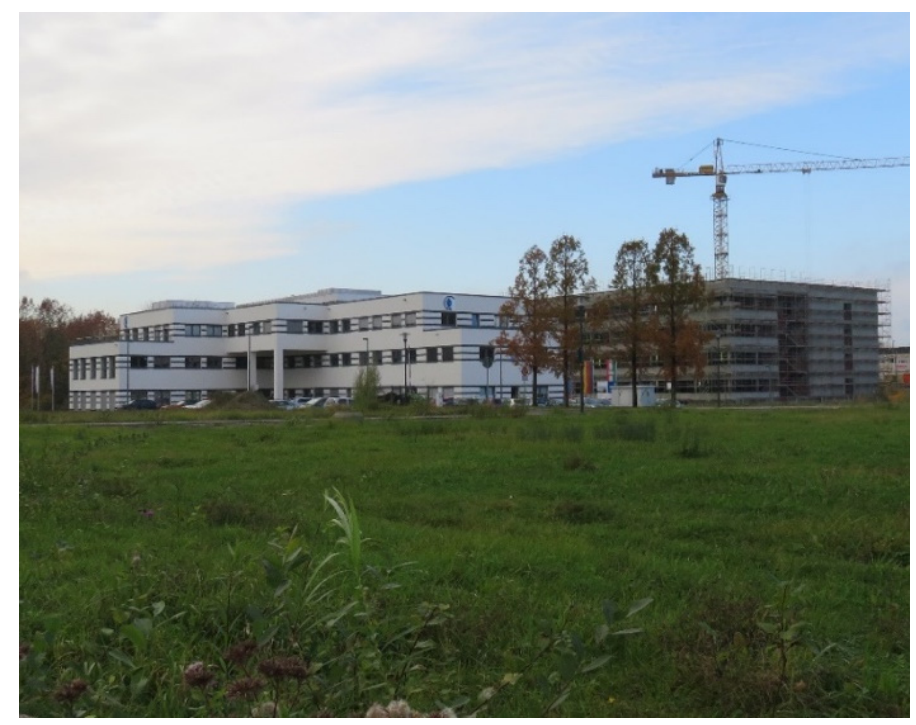

Figure 4. Health campus-development 2017. Source: Jakob Schackmar. 
Bochum initiated the project health campus in 2006 to expand on already existing strengths and the potential of 60,000 students routed in the Ruhr University Bochum (RUB) next to it. The health campus aimed to attract the know-how and innovation coming from the medical university and start-ups in the health sector, as well as from its close links to other departments at RUB [33,59]. Over the years, many firms and institutions have decided to locate at health campus, following the establishment of the "Hochschule für Gesundheit", (University of Applied Health Science). The aim of the project was to bring public and private firms and institutions (spatially) together to enable greater benefits and gains for all stakeholders [33].

In doing so, Bochum is actively taking on two aspects of the same coin:

1. In general, a city's educational infrastructure counts as an important basis for successful economic development in the respective municipality, as it provides well-trained specialists for the local and regional labour market and creates jobs. Depending on the size of the (higher) educational institution, the number of jobs varies [60] (pp. 6-7). The city of Bochum is home to 57,000 university students at nine local universities, providing 10,000 direct jobs and uncounted indirect ones. Subsequently, education is already an important economic factor [33,61].

2. The importance of future health technologies and health infrastructures is increasing. These include, for example, information technology and big data, as well as the possibilities of increasingly individualized medical care, improved diagnosis and therapy, and also new methods for prevention and rehabilitation [59] (p. 9). The medical university located at Bochum consists of eight special clinics and links institutions of higher and lower medical education [33].

Bringing together these two major economic and future-oriented locational factors of eds and meds creates a great potential for the city of Bochum. The medical university and its medical clinics and centres are important "industrial and enterprise clusters". Here, strong contributions are made to the economic foundation of their local municipalities and beyond into the region. In general, cities are able to generate tangible benefits such as employment and added value, as well as intangible benefits such as prestige and a change of image [62]. Consequently, Bochum has started to promote and support the combined development of these innovative sectors.

The two parts of health economics and health technology, as well as the link with research and education, represents an innovative mix. Generally speaking, the healthcare industry is one of the largest parts of the developed economies. Especially in Germany, the health sector is a job-providing engine that is expected to grow even further with an aging society [59] (p. 9).

Particularly efficient and productive is the combination of cross-sectoral efforts linking professions of supply, science, and economics. University institutes are associated with facilities of research, as well as its practice, production, and administration. The city of Bochum has created exactly this constellation with its project Health Campus, in the university area of the city, outside the downtown area. Connected by a transit and development corridor, it aims to spread its revitalisation efforts across Bochum.

The spatial and functional connection of the Medical University with the University of Applied Health Science, the health institutions and administrations of the state of North Rhine Westphalia, public and private research institutes, companies from the industry, and the manufacturing industry makes an important contribution to framing and mastering the increasing number of innovations in healthcare. With the project Health Campus, Bochum is providing a place for companies and institutions to develop in close proximity to each other and benefit from their respective potentials. This strengthens the economic prospects of Bochum as a whole and could counteract the loss of jobs in the manufacturing industry as well as reduce shrinkage [33]. After successfully establishing Bochum as a centre for the health industry, the city followed up on its own success by establishing yet another future-oriented cluster. Again building on the know-how and expertise at RUB and a small company cluster left over from the time when Nokia used to produce in Bochum, the city 
has established an IT cluster focusing on IT security. Part of the city's development strategy is also the redevelopment of brownfield sites often located right within the city limits. One of these examples is the former plant of car manufacturer Opel. At this central location, the city is now developing new residential areas, research facilities, and start-up clusters.

\subsubsection{Reflection on the Case}

The city of Bochum, as its surroundings, was affected early on by economic change. In the competition among the Ruhr area's cities, Bochum identified its niche and initiated an education and medicine strategy to revitalise itself. Not only is eds and meds a field of the economy that is likely to grow in importance in the future, but Bochum is already home to companies and institutions working in the field. The goal is to build on existing strengths for revitalisation and not create something new that is unsure to succeed.

Focusing on this approach can be classified being a sustainable strategy in growing the urban economy, in the sense that the approach draws from the existing strengths of higher and lower education as well as medical schools and education with private firms and institutions and not initiates in an experimental new way, which would be unsure to succeed and would presumably take longer.

The promotion and support of industrial and enterprise clusters in eds and meds with cross-sectoral efforts linking the professions of supply, science, and economics is channelled into the city's health campus project. The companies working in the field are more likely to stay in Bochum in the future and generate new jobs.

Located in the university area of town, the effects of physical revitalisation are linked to the downtown area with a development corridor, aimed at revitalizing more than one part of town, though it is not yet clear if this will materialize. Having a different thematic approach to Cleveland, the corridor strategy to physically connect the projects to the downtown areas, and consequently the rest of town, are quite similar, as well as stirring up of development between the new development cluster and the inner city, spreading the effects of development over a broader part of town. Moreover, it cannot be determined from the research conducted in Bochum if the city's administration has intentionally initiated with a sustainable development strategy in mind or if the effects of the initiatives are coincidentally aiming at the same outcome.

\section{Conclusions}

What is the role of substitute industries for revitalizing shrinking cities? The cases displayed above highlight substitute industries from different angles. We found that in Germany (Bochum) and the USA (Cleveland) alike, knowledge economy and eds and meds were utilized as economic starting points to actively steer cities in a new direction away from shrinkage. Comparing both cases, it seems that, with the new substitute industries, more jobs and prosperity are on the horizon.

In general, the downward spirals caused vast losses of jobs in the case study cities, and although we have seen traces of success in the revitalizing of the economies, the substitute industries which were created are so far unable to become job generators to the same extent. This became apparent during the interviews in both cities and the project workshop. However, as substitute industries cannot serve as an instant remedy to solve structural problems in shrinking cities, there will most likely be positive effects in the long-term.

Yet there are still loose ends and further research requirements. By focusing on attracting new labour to the cities, people who have lost their jobs in mining or manufacturing may be disconnected from this development. Thus, there is a demand to examine how efficient these programs are at reaching poorer, less qualified citizens-after all, sustainability also aims at strengthening social aspects.

Therefore, sustainable strategies for shrinking cities would encompass a range of aspects in environmental, social, and economic terms, and rely on the cities' existing capacities. When it comes to making use of local economic potentials to promote and create new jobs, it should be considered that those projects deliver added value for the city. 
In addition, a focus should be placed on environmental aspects, such as the recycling of (brownfield) land, as well as jobs in innovative branches, which might be environmental industries (e.g., bioeconomy). Moreover, it should be carefully considered whether the existing building structures can be reused or rebuilt for other types of uses.

Furthermore, the new substitute industries are largely dependent on clusters around a few key sectors. For this reason, the risk of creating another type of monostructural economic base should be considered. Yet, as they are more diverse then the economies of the past, and because the new industries and jobs are very location-based, unlike the old ones, they are not at risk of being relocated, therefore they could be counted as being more sustainable for a number of reasons.

In this context, sustainability can be defined as the cities being able to stop the shrinkage process and stabilizing or even growing again, becoming somewhat viable as a town. Both cities have learned from the upheaval of the past that viability can only be achieved through economic revitalization and the creation of new jobs through substitute industries.

However, if the case study cities, with their two development hot spots, can achieve this for the whole of their respective city remains to be seen. The development corridors, connecting the projects with the downtown areas, are first attempts at revitalizing other parts of town, but the question is whether a full-scale redevelopment is needed. It is unlikely that the cities will ever regain the population numbers of the past.

Sustainability as a development goal would also need to see a physical reduction in the size of the built and unused parts of these cities. The research results presented here suggest that shrinking cities, in the beginning, did perhaps not consciously follow sustainability strategies, but it is becoming apparent that these cities are feeling the pressure to actively address the issue of sustainability in regards to the future-oriented liveability of their cities.

All in all, it appears to be possible to learn from cities when it comes to substitute industries, and, in the cases Cleveland and Bochum, urban planning and urban (re-)development also imply aspects of sustainability. Yet, the case study cities are on a viable path of doing so. Thus, further research is needed in order to broaden these findings to a larger number of cities within Germany and the USA, and also beyond these countries, in order to answer the question of whether shrinking cities can turn to sustainability as a strategic path, given their past experiences.

Author Contributions: Conceptualization: J.S. and K.P.; methodology: K.P.; validation: J.S., R.F., K.P.; investigation: J.S., R.F., K.P.; writing—original draft preparation: J.S.; writing—review and editing: R.F., K.P.; visualization: K.P.; supervision: K.P. All authors have read and agreed to the published version of the manuscript.

Funding: This research received no external funding.

Conflicts of Interest: The authors declare no conflict of interest.

\section{References}

1. Beauregard, R.A. Aberrant Cities. Urban Population Loss in the United States, 1820-1930. Urban Geogr. 2003, 24, 672-690. [CrossRef]

2. Bontje, M. Facing the challenge of shrinking cities in East Germany: The case of Leipzig. GeoJournal 2004, 61, 13-21. [CrossRef]

3. Gestring, N.; Glasauer, H.; Hannemann, C.; Petrowsky, C.; Pohlan, J. Jahrbuch Stadtregion 2004/5: Schwerpunkt: Schrumpfende Städte; VS. Verl. für Sozialwissenschaften: Wiesbaden, Germany, 2005.

4. Oswalt, P. Shrinking Cities: International Research; Hatje Cantz: Ostfildern-Ruit, Germany, 2006; Volume 1.

5. Siedentop, S.; Wiechmann, T. Zwischen Schrumpfung und Reurbanisierung-Stadtentwicklung in Dresden 1990. Raumplanung 2007, 131, 57-62.

6. Hollander, J.B.; Pallagst, K.; Popper, F.J. Planning Shrinking Cities. Prog. Plan. 2009, 72, 223-232.

7. Ryan, B.D. Design After Decline: How America Rebuilds Shrinking Cities; University of Pennsylvania Press: Philadelphia, PA, USA, 2012.

8. Mallach, A.; Brachman, L. Regenerating America's Legacy Cities; Lincoln Institute of Land Policy: Cambridge, MA, USA, 2013.

9. Pallagst, K.; Wiechmann, T.; Martinez-Fernandez, C. Shrinking Cities: International Perspectives and Policy Implications; Routledge: New York, NY, USA, 2014. 
10. Pallagst, K. Shrinking cities: Planning challenges from an international perspective. Urban Infill 2008, 1, 6-16.

11. Wolff, M.; Wiechmann, T. Urban growth and decline: Europe's shrinking cities in a comparative perspective 1990-2010. Eur. Urban Reg. Stud. 2017, 25, 122-139. [CrossRef]

12. Youngstown City Hall. Youngstown 2010 Citywide Plan. Available online: https:/ /www.wrtaonline.com/wp-content/uploads / 2020/09/Youngstown-2010-Citywide-Plan-full.pdf (accessed on 2 August 2021).

13. Imagine Flint Website. Available online: https:/ / www.imagineflint.com (accessed on 2 August 2021).

14. Stadt Zwickau. Integriertes Stadtentwicklungskonzept Zwickau-INSEK Zwickau 2030-LEITBILD. Available online: https: //www.zwickau.de/media/downloads/image/01_buerger/insek/INSEKLeitbild_130911.pdf (accessed on 2 August 2021).

15. Pallagst, K.; Fleschurz, R.; Nothof, S.; Uemura, T. Shrinking cities-Implications for planning cultures? Urban Stud. 2021, 58, 164-181. [CrossRef]

16. Pallagst, K. Substitute industries-Panacea or false hope for shrinking cities? disP Plan. Rev. 2017, 53, 82-83. [CrossRef]

17. United-Nations. Sustainable Cities and Human Settlements. 2020. Available online: https://sdgs.un.org/topics/sustainable-citie s-and-human-settlements (accessed on 2 August 2021).

18. Audirac, I. Introduction: Shrinking Cities from marginal to mainstream: Views from North America and Europe. Cities 2017, 75, 1-5. [CrossRef]

19. Blanco, H.; Alberti, M.; Olshansky, R.; Chang, S.; Wheeler, S.M.; Randolph, J.; London, J.B.; Hollander, J.B.; Pallagst, K.M.; Schwarz, T.; et al. Shaken, shrinking, hot, impoverished and informal: Emerging research agendas in planning. Prog. Plan. 2009, 72, 195-250. [CrossRef]

20. Henckel, D. Stadtumbau West Website. Available online: https://stadtumbauwest.de/konzept/pptHenckel.pdf (accessed on 2 August 2021).

21. Liebmann, H.; Kühn, M. Schaader Stiftung Website. Available online: https://www.schader-stiftung.de/themen/stadtentwickl ung-und-wohnen/fokus/konversion/artikel/regenerierung-schrumpfender-staedte-stadtumbau-als-ansatz-fuer-integrierte -strategien (accessed on 2 August 2021).

22. Rink, D.; Haase, A.; Grossmann, K.; Couch, C.; Cocks, M. From Long-Term Shrinkage to Re-Growth? The Urban Development Trajectories of Liverpool and Leipzig. Built Environ. 2012, 38, 162-178. [CrossRef]

23. ILS-NRW. Stadt-Entwicklung zwischen Wachstum und Schrumpfung. Werkstattgespräch; ILS: Dortmund, Germany, 2003 ; Volume 188.

24. Ahuis, H. Eröffnung. In Schrumpfende Städte Fordern Neue Strategien für Die Stadtentwicklung: Aus dem Leerstand in Neue Qualitäten; Deutsche Akademie für Städtebau und Landesplanung (DASL), Ed.; Müller und Busmann: Wuppertal, Germany, 2002.

25. Sánchez-Moral, S. The mobility of 'creative workers' and their potential contribution to the recovery of old industrial cities in Spain. Town Plan. Rev. 2017, 88, 93-107. [CrossRef]

26. Winkel, R. Schrumpfung und ihre Siedlungsstrukturellen Wirkungen. Raumplanung 2002, 101, 99-103.

27. BBSR. Stadtumbau West-Eine Zwischenbilanz. Statusbericht 2009 der Bundestransferstelle Stadtumbau West; BMVBS: Berlin, Germany, 2010.

28. Gatzweiler, H.P.; Milbert, A. Schrumpfende Städte wachsen und wachsende Städte schrumpfen. Inf. Raumentwickl. 2009, 7, 443-455.

29. Franz, P. Regional politische Optionen für schrumpfende Städte. Polit. Zeitgesch. 2005, 3, 10-16.

30. Ellrich, M.; Neuhaus, C. Infoblatt Schrumpfende Städte-Shrinking Cities. Available online: https://www.klett.de/sixcms/detail .php?template=terrasse_artikel_layout_pdf\&art_id=1004509 (accessed on 2 August 2021).

31. Glock, B. Stadtpolitik in Schrumpfenden Städten-Duisburg und Leipzig im Vergleich; VS für Sozialwissenschaften: Dortmund, Germany, 2006.

32. Pallagst, K.; Vargas-Hernández, J.; Hammer, P. Green innovation areas as contested spaces? Investigating potentials and risks of revitalization schemes in shrinking cities. In Proceedings of the AESOP annual congress 2017, Lisbon, Portugal, 11-14 July 2017.

33. Peuling, J. Business Development Agency Bochum, Bochum, Germany. 2017. Unpublished interview.

34. Pallagst, K.; Fleschurz, R.; Said, S. What drives planning in a shrinking city? Tales from two German and two American cases. Town Plan. Rev. 2017, 88, 15-28. [CrossRef]

35. Pallagst, K.; Mulligan, H.; Cunningham-Sabot, E.; Fol, S. The shrinking city awakens: Perceptions and strategies on the way to revitalisation? Town Plan. Rev. 2017, 88, 9-13. [CrossRef]

36. Li, H.; Dong, L.; Ren, J. Industrial symbiosis as a countermeasure for resource dependent city: A case study of Guiyang, China. J. Clean. Prod. 2015, 107, 252-266. [CrossRef]

37. Kunzmann, K.R. Medium-Sized Towns, Strategic Planning and Creative Governance. In Making Strategies in Spatial Planning. Urban and Landscape Perspectives; Cerreta, M., Concilio, G., Monno, V., Eds.; Springer: Dordrecht, Germany, 2017; Volume 9, pp. 27-45.

38. Pallagst, K. Shrinking Cities in the United States of America: Three Cases, Three Planning Stories. In The Future of Shrinking Cities: Problems, Patterns and Strategies of Urban Transformation in a Global Context; Pallagst, K., Aber, J., Audirac, I., Cunningham-Sabot, E., Fol, S., Martinez-Fernandez, C., Moraes, S., Mulligan, H., Vargas-Hernandez, J., Wiechmann, T., et al., Eds.; IURD: Berkeley, CA, USA, 2009; pp. 81-88. 
39. Audirac, I. Urban Shrinkage Amid Fast Metropolitan Growth (Two Faces of Contemporary Urbanism). Available online: https://www.researchgate.net/profile/Ivonne-Audirac/publication/228815324_Urban_Shrinkage_Amid_Fast_Metropolitan_ Growth_Two_Faces_of_Contemporary_Urbanism/links/56878db308aebccc4e1517ef/Urban-Shrinkage-Amid-Fast-Metropoli tan-Growth-Two-Faces-of-Contemporary-Urbanism.pdf (accessed on 2 August 2021).

40. Sorensen, A. Taking Path Dependence Seriously: A historical institutionalist research agenda in planning history. Plan. Perspect. 2014, 30, 17-38. [CrossRef]

41. United-Nations. Report of the World Commission on Environment and Development: Our Common Future; UN: New York, NY, USA, 1987.

42. Krellenberg, K.; Bergsträßer, H.; Bykova, D.; Kress, N.; Tyndall, K. Urban Sustainability Strategies Guided by the SDGs-A Tale of Four Cities. Sustainability 2019, 11, 1116. [CrossRef]

43. United-Nations. Earth Summit-Agenda 21. In Proceedings of the United Nations Conference on Environment \& Development, Rio de Janerio, Brazil, 3-14 June 1992.

44. Wiechmann, T.; Pallagst, K. Urban Shrinkage in Germany and the USA: A Comparison of Transformation Patterns and Local Strategies. Int. J. Urban Reg. Res. 2012, 36, 261-280. [CrossRef] [PubMed]

45. Spraul, K.; Pallagst, K.; Jungbauer, A. Nachhaltige Stadtplanung und Steuerung der Flächennutzung-Die Green-Belt-Politik in Schottland und Lerneffekte für die deutsche kommunale Planung. DMS Mod. Staat 2016, 9, 11-12. [CrossRef]

46. Otner, S.M.G. Most Different Systems Design. In Encyclopedia of Case Study Research; Mills, A.J., Durepos, G., Wiebe, E., Eds.; Sage Publications: Thousand Oaks, CA, USA, 2010.

47. Pierre, J. Comparing Urban Governance-Uncovering Complex Causalities. Urban Aff. Rev. 2005, 40, 446-462. [CrossRef]

48. Booth, P. Culture, planning and path dependence: Some reflections on the problem of comparison. Town Plan. Rev. 2011, 82, 13-28. [CrossRef]

49. Yin, R.K. Case Study Research and Applications. Design and Methods; Sage Publications: Thousand Oaks, CA, USA, 2003.

50. Göb, R. Die Schrumpfende Stadt. Arch. Kommunalwiss. 1977, 16, 149-177.

51. Häussermann, H.; Siebel, W. Neue Urbanität; Suhrkamp: Frankfurt am Main, Germany, 1987.

52. Pallagst, K.; Wiechmann, T. Shrinking smart: Städtische Schrumpfungsprozesse in den USA. In Jahrbuch StadtRegion, Schwerpunkt "Schrumpfende Städte"; für Sozialwissenschaften: Wiesbaden, Germany, 2005.

53. Pallagst, K. The planning research agenda: Shrinking cities-A challenge for planning cultures. Town Plan. Rev. 2010, 81, I-IV. [CrossRef]

54. Pallagst, K. Das Ende der Wachstumsmaschine: Schrumpfende Staedte in den USA. Berl. Debatte Initial 2007, 18, 4-13.

55. Heemeyer, C. Flexibilisierung der Erfordernisse der Raumordnung: Aktuelle Rechtslage und Ausblick auf Alternative Steuerungsmodelle; Lexxion Verlagsgesellschaft: Muenster, Germany, 2006.

56. Pallagst, K.; Fleschurz, R.; Nothof, S.; Uemura, T. PlanShrinking ${ }^{2}$-Trajectories of Planning Cultures in Shrinking Cities: The cases Cleveland/USA, Bochum/Germany, and Nagasaki/Japan. IPS Working Paper. 2018. Available online: https://www.ru.uni-kl.de / fileadmin/intplan/Publikationen/Working_Paper_Series/IPS_WP_1_2018_-_PlanShrinking.pdf (accessed on 2 August 2021).

57. Austin, J. Tale of Two Rust Belts: Higher Education is Driving Rust Belt Revival, but Risks Abound. The Brookings Institution Website. Available online: https:/ /www.brookings.edu/blog/the-avenue/2017/12/19/tale-of-two-rust-belts-higher-educati on-is-driving-rust-belt-revival-but-risks-abound (accessed on 2 August 2021).

58. Cleveland-Foundation. Cleveland's Greater University Circle Initiative. Building a 21st Century City through the Power of Anchor Institution Collaboration; Cleveland Foundation: Cleveland, OH, USA, 2013.

59. Schober, O. Zukunftsfähige Gesundheitsinfrastrukturen. In Stadt der Zukunft—Strategieelemente einer Nachhaltigen Stadtentwicklung; Weinert, K., Beckmann, K.J., Encarnação, J., Herzog, O., Höcker, H., Kuhn, A., Mühlhäuser, M., Schober, O., Spath, D., Thoma, K., Eds.; Deutsche Akademie der Technikwissenschaften: München, Germany, 2014; pp. 9-15.

60. BMWI. Modellvorhaben Daseinsvorsorge 2030_Innovativ und Modern—Eine Antwort auf den Demografischen Wandel; BMWI: Berlin, Germany, 2014.

61. Bochum-Marketing. UniverCity Bochum. Available online: https:/ /www.univercity-bochum.de (accessed on 2 August 2021).

62. Ehlenz, M.M.; Birch, E.L.; Agness, B. The Power of Eds and Meds- Urban Universities Investing in Neighborhood Revitalization and Innovation Districts; University of Pennsylvania: Pennsylvania, PA, USA, 2014. 